\title{
Treatment of Older Patients with Mantle-Cell Lymphoma
}

\author{
H.C. Kluin-Nelemans, E. Hoster, O. Hermine, J. Walewski, M. Trneny, \\ C.H. Geisler, S. Stilgenbauer, C. Thieblemont, U. Vehling-Kaiser, J.K. Doorduijn, \\ B. Coiffier, R. Forstpointner, H. Tilly, L. Kanz, P. Feugier, M. Szymczyk, M. Hallek, \\ S. Kremers, G. Lepeu, L. Sanhes, J.M. Zijlstra, R. Bouabdallah, P.J. Lugtenburg, \\ M. Macro, M. Pfreundschuh, V. Procházka, F. Di Raimondo, V. Ribrag, \\ M. Uppenkamp, M. André, W. Klapper, W. Hiddemann, M. Unterhalt, \\ and M.H. Dreyling
}

The authors' full names, degrees, and affiliations are listed in the Appendix. Address reprint requests to Dr. Kluin-Nelemans at the Department of Hematology, University Medical Center Groningen, Hanzeplein 1, 9700 RB Groningen, the Netherlands, or at j.c.kluin@umcg.nl.

N EnglJ Med 2012;367:520-31. DOI: 10.1056/NEJMoal200920

Copyright @ 2012 Massachusetts Medical Society.

\section{ABSTRACT}

\section{BACKGROUND}

The long-term prognosis for older patients with mantle-cell lymphoma is poor. Chemoimmunotherapy results in low rates of complete remission, and most patients have a relapse. We investigated whether a fludarabine-containing induction regimen improved the complete-remission rate and whether maintenance therapy with rituximab prolonged remission.

\section{METHODS}

We randomly assigned patients 60 years of age or older with mantle-cell lymphoma, stage II to IV, who were not eligible for high-dose therapy to six cycles of rituximab, fludarabine, and cyclophosphamide (R-FC) every 28 days or to eight cycles of rituximab, cyclophosphamide, doxorubicin, vincristine, and prednisone (R-CHOP) every 21 days. Patients who had a response underwent a second randomization to maintenance therapy with rituximab or interferon alfa, each given until progression.

\section{RESULTS}

Of the 560 patients enrolled, 532 were included in the intention-to-treat analysis for response, and 485 in the primary analysis for response. The median age was 70 years. Although complete-remission rates were similar with R-FC and R-CHOP $(40 \%$ and $34 \%$, respectively; $\mathrm{P}=0.10)$, progressive disease was more frequent with $\mathrm{R}-\mathrm{FC}(14 \%$, vs. $5 \%$ with R-CHOP). Overall survival was significantly shorter with R-FC than with R-CHOP (4-year survival rate, $47 \%$ vs. $62 \%$; $\mathrm{P}=0.005$ ), and more patients in the R-FC group died during the first remission ( $10 \%$ vs. $4 \%$ ). Hematologic toxic effects occurred more frequently in the R-FC group than in the R-CHOP group, but the frequency of grade 3 or 4 infections was balanced (17\% and 14\%, respectively). In 274 of the 316 patients who were randomly assigned to maintenance therapy, rituximab reduced the risk of progression or death by $45 \%$ (in remission after 4 years, $58 \%$, vs. $29 \%$ with interferon alfa; hazard ratio for progression or death, 0.55 ; $95 \%$ confidence interval, 0.36 to $0.87 ; \mathrm{P}=0.01$ ). Among patients who had a response to R-CHOP, maintenance therapy with rituximab significantly improved overall survival (4-year survival rate, $87 \%$, vs. $63 \%$ with interferon alfa; $\mathrm{P}=0.005$ ).

\section{CONCLUSIONS}

R-CHOP induction followed by maintenance therapy with rituximab is effective for older patients with mantle-cell lymphoma. (Funded by the European Commission and others; ClinicalTrials.gov number, NCT00209209.) 
P ATIENTS WITH MANTLE-CELL LYMPHOMA typically present with extensive disease and involvement of multiple lymph nodes as well as the spleen, bone marrow, blood, and gastrointestinal tract. The median age at diagnosis is about 65 years. ${ }^{1,2}$ Standard therapy for these patients consists of chemotherapy (e.g., the CHOP regimen, consisting of cyclophosphamide, doxorubicin, vincristine, and prednisone) combined with the anti-CD20 monoclonal antibody rituximab (e.g., R-CHOP). ${ }^{2-4}$ Only a minority of patients have a complete remission, and relapse or progression usually occurs within 2 to 3 years, resulting in an overall survival of less than 5 years.

To improve this grim prognosis, we attempted to establish a more effective induction therapy, resulting in an increased rate of complete remission, and better postinduction strategies, such as maintenance therapy, that would prolong the duration of remission. Several previous studies have investigated fludarabine-containing regimens, which showed high efficacy in follicular lymphoma and relapsed mantle-cell lymphoma. ${ }^{4-7} \mathrm{~A}$ trial of a combination of fludarabine, cyclophosphamide with or without mitoxantrone, and rituximab showed promising results. ${ }^{8}$ Considering the risk of cardiac toxic effects in older patients, treatments that excluded anthracyclines were particularly attractive.

Maintenance therapy with interferon alfa showed a tendency toward prolongation of progression-free survival in patients with mantle-cell lymphoma and was therefore considered standard therapy in a previous trial. ${ }^{9}$ Maintenance therapy with rituximab had significantly improved the duration of response in patients with relapsed follicular lymphoma or mantle-cell lymphoma ${ }^{10}$ and seemed to be a promising alternative, given the strong CD20 expression on mantle-cell-lymphoma cells.

Therefore, in 2004, we initiated a double-randomized intergroup trial with two objectives. First, we compared the rates of response to an induction regimen consisting of fludarabine, cyclophosphamide, and rituximab (R-FC) and an induction regimen with R-CHOP. Second, we studied the duration of remission; patients who had a response were randomly assigned to maintenance therapy with rituximab or interferon alfa (see Fig. S1 in the Supplementary Appendix, available with the full text of this article at NEJM.org).

\section{METHODS}

\section{CHARACTERISTICS OF THE PATIENTS}

Eligible patients had newly diagnosed, histologically confirmed mantle-cell lymphoma, ${ }^{1}$ Ann Arbor stage II to IV; were 66 years of age or older or were 60 to 65 years of age if they were ineligible for high-dose treatment; and had an Eastern Cooperative Oncology Group performance status of 2 or less (with 0 indicating asymptomatic, 1 symptomatic but ambulatory, and 2 symptomatic and in bed less than half the day). Pathological findings were centrally reviewed by the Pathology Panel of the European Mantle Cell Lymphoma Network. ${ }^{11}$ Patients were excluded if they had a leukocyte count of less than $2 \times 10^{9}$ per liter, a platelet count of less than $100 \times 10^{9}$ per liter, a liver-enzyme level greater than 3 times the upper limit of the normal range, a bilirubin level greater than 2.5 times the upper limit of the normal range, or a creatinine level greater than 2 times the upper limit of the normal range, if these counts or levels were unrelated to mantle-cell lymphoma. Additional exclusion criteria were involvement of the central nervous system, a history of autoimmune cytopenia, hypersensitivity to murine antibodies, other cancers, and serious cardiac, pulmonary, neurologic, or endocrine disease or other conditions that might interfere with adherence to the study.

\section{STUDY PROTOCOL}

The study was performed in accordance with the updated Declaration of Helsinki, and all patients provided written informed consent. Both randomizations were performed centrally at the data center of the European Mantle Cell Lymphoma Network or at the data center of the HematoOncology Foundation for Adults in the Netherlands (HOVON) and were stratified according to study group, age, and the International Prognostic Index ${ }^{12}$ risk profile. The second randomization was also stratified according to the induction regimen and the category of response. On behalf of the European Mantle Cell Lymphoma Network, the first, second, penultimate, and last authors designed the study and vouch for the accuracy and completeness of the data and analysis and the fidelity of the study to the protocol; these authors wrote the manuscript and made the decision to submit it for publication. The second and penultimate authors gathered and analyzed the data. 
Roche Pharmaceuticals and Schering-Plough supplied maintenance medication at no cost but played no role in the design or execution of the study, the data collection or analysis, or the writing of the manuscript. The protocol, including the statistical analysis plan, is available at NEJM.org.

\section{INDUCTION TREATMENT}

Induction therapy consisted of either R-FC or R-CHOP open-label chemoimmunotherapy. Rituximab was added to the chemotherapy when the count of circulating lymphoma cells was less than $10 \times 10^{9}$ per liter. The R-FC regimen consisted of rituximab at a dose of $375 \mathrm{mg}$ per square meter of body-surface area given intravenously on day 1 (maximum dose, $750 \mathrm{mg}$ ), fludarabine at a dose of $30 \mathrm{mg}$ per square meter given intravenously on days 1 through 3 , and cyclophosphamide at a dose of $250 \mathrm{mg}$ per square meter given intravenously on days 1 through 3 . The regimen was repeated at day 29 for six cycles. The R-CHOP regimen consisted of rituximab at a dose of $375 \mathrm{mg}$ per square meter (maximum dose, $750 \mathrm{mg}$ ), cyclophosphamide at a dose of $750 \mathrm{mg}$ per square meter, doxorubicin at a dose of $50 \mathrm{mg}$ per square meter, and vincristine at a dose of $1.4 \mathrm{mg}$ per square meter (maximum dose, $2 \mathrm{mg}$ ), all given intravenously on day 1 , and oral prednisone at a dose of $100 \mathrm{mg}$ given on days 1 through 5 . The regimen was repeated at day 22 for eight cycles. If neurologic toxic effects occurred, the dose of vincristine was modified at the physician's discretion.

Subsequent courses were postponed for 1 week if the leukocyte count was less than $4 \times 10^{9}$ per liter or the platelet count was less than $100 \times 10^{9}$ per liter. Doses of fludarabine, cyclophosphamide, and doxorubicin in subsequent cycles were modified if myelosuppression was persistent (see the Supplementary Appendix). If progression occurred, induction was stopped.

\section{MAINTENANCE TREATMENT}

The option to participate in the second randomization was offered to patients who had a response to the induction regimen, a leukocyte count greater than $3 \times 10^{9}$ per liter, and a platelet count greater than $100 \times 10^{9}$ per liter (or greater than $75 \times 10^{9}$ per liter, according to a protocol amendment in 2009). Open-label maintenance therapy started immediately after the date of the second randomization and continued until progression. Rituximab was continued at a dose of $375 \mathrm{mg}$ per square meter every 2 months. Standard interferon alfa was administered subcutaneously at a dose of 3 million units three times per week; pegylated interferon alfa was administered at a dose of $1 \mu \mathrm{g}$ per kilogram of body weight per week. If any toxic effect of grade 2 or 3 occurred, the dose was reduced by 30 to $50 \%$; for any toxic effect of grade 4 , treatment with interferon alfa was interrupted until recovery, then resumed at $50 \%$ of the previous dose, and gradually increased if serious adverse events did not occur.

\section{STAGING PROCEDURES, RESPONSE MONITORING, AND END POINTS}

Baseline measurements consisted of computed tomography (CT) of the neck, chest, abdomen, and pelvis, and a trephine biopsy of bone marrow; additional investigations were performed if clinically indicated. The response was evaluated according to the 1999 consensus criteria ${ }^{13}$ (see the Supplementary Appendix). CT studies and testing for other initially positive findings were repeated at midterm (i.e., after four cycles of R-CHOP or three cycles of R-FC) and at the end of the induction phase. The response to induction chemotherapy was determined 4 weeks after the last cycle. During follow-up, response evaluations were performed twice yearly until progression.

The primary prespecified end point for the comparison of the induction regimens was the rate of complete remission (excluding unconfirmed complete remissions). For the primary analysis, the response was classified as a premature stop if the induction regimen was stopped either earlier than midterm, in patients without progression, or when less than two thirds of the cycles had been completed, in patients who had a response. The primary prespecified end point for the comparison of maintenance regimens was the duration of remission, which was calculated as the interval from the last day of induction therapy until progression or death from any cause. The secondary end points were the overall response rate, the time to treatment failure (defined as stable disease, relapse, progression, or death) from the start of induction therapy, overall survival, and toxic effects. 


\section{STATISTICAL ANALYSIS}

The overall response rate and the duration of remission were monitored by sequential analyses ${ }^{14}$ with planned interim analyses. The study was designed to have $95 \%$ power to detect an increase in the rate of complete remission from $50 \%$ after R-CHOP to $65 \%$ after R-FC, at a one-sided significance level of $5 \%$. For the duration of remission, the study was designed to have $95 \%$ power to detect a $40 \%$ reduction in the risk of progression or death with rituximab, as compared with interferon alfa, at a two-sided significance level of $5 \%$. We calculated that we would need to enroll a total of 570 patients (allowing for withdrawals from the study), and that a maximum of 240 events, with adjustment for the sequential design (Fig. S2A in the Supplementary Appendix), would be needed to compare the duration of remission with the two maintenance regimens.

As prespecified in the protocol, the primary analysis included patients with mantle-cell lymphoma of stage II to IV who underwent randomization and had started treatment in accordance with the randomization result; data for patients receiving maintenance therapy who started another antilymphoma therapy without progression were censored at the time of the protocol violation. All secondary efficacy analyses were performed according to the intention-to-treat principle, with all patients who underwent randomization included and protocol violations ignored. For safety analyses, patients were evaluated as treated.

Remission rates and other categorical variables were compared by means of Fisher's exact test; time-to-event variables were described with the use of Kaplan-Meier estimates and compared with use of the log-rank test. P values for sequentially monitored end points were reported with adjustment for interim analyses. For the maintenancetherapy comparison, a potential interacting effect by type of induction therapy was explored by means of multiple Cox regression. In the case of a significant interaction, stratified effects were reported. The calculation of the sample size and the sequential monitoring were performed with the use of PEST software, version 3 (Applied Statistics Department, University of Reading, Reading, United Kingdom). Statistical analysis was performed with the use of SAS software, version 9.2 (SAS Institute).

\section{RESULTS}

\section{INDUCTION TREATMENT}

Between January 2004 and October 2010, a total of 560 patients from eight countries were randomly assigned to chemotherapy with R-CHOP or R-FC; 532 of these patients were included in the intentionto-treat analysis and 485 were included in the primary analysis (Fig. 1A). Table 1 and Table S1 in the Supplementary Appendix show the demographic and clinical characteristics of the patients.

The rate of complete remissions at the end of induction therapy was not significantly higher after R-FC (98 of 246 patients [40\%]) than after R-CHOP (81 of 239 [34\%]) ( $\mathrm{P}=0.10$ with a onesided test, in the primary analysis). The overall response rate was lower after R-FC than after R-CHOP but the difference was not significant (192 of 246 patients [78\%] and 206 of 239 [86\%], respectively; $\mathrm{P}=0.06$, with adjustment for interim analyses), and complete-remission rates, including unconfirmed complete remission, were also similar ( $53 \%$ and $49 \%$, respectively). The rate of progression was higher during R-FC than during R-CHOP ( $14 \%$ vs. $5 \%$ ). The intention-to-treat analysis yielded identical results (Table S2 in the Supplementary Appendix). After a median followup of 37 months, the time to treatment failure was similar with R-FC and R-CHOP (median, 26 and 28 months, respectively) (Fig. 2A) with a similar duration of remission (37 and 36 months, respectively).

However, the overall survival was significantly shorter after R-FC than after R-CHOP (survival rate at 4 years, $47 \%$ vs. $62 \% ; \mathrm{P}=0.005$; hazard ratio for death, 1.50; 95\% confidence interval [CI], 1.13 to 1.99) (Fig. 2B). Of the 560 patients, 199 died 115 of 280 patients in the R-FC group and 84 of 280 in the R-CHOP group. Causes of death were mainly related to progression of lymphoma (64 patients in the R-FC group vs. 47 in the R-CHOP group). In addition, more patients who received R-FC died from infection, as compared with those who received R-CHOP (19 vs. 12), or from a secondary cancer ( 9 vs. 3 ). The remaining causes of death in the R-FC and R-CHOP groups, respectively, were related to cardiac causes ( 4 and 9 patients), pulmonary causes (3 and 2), central nervous system bleeding or ischemia ( 2 and 1 ), leukoencephalopathy (1 and 1), or unknown 


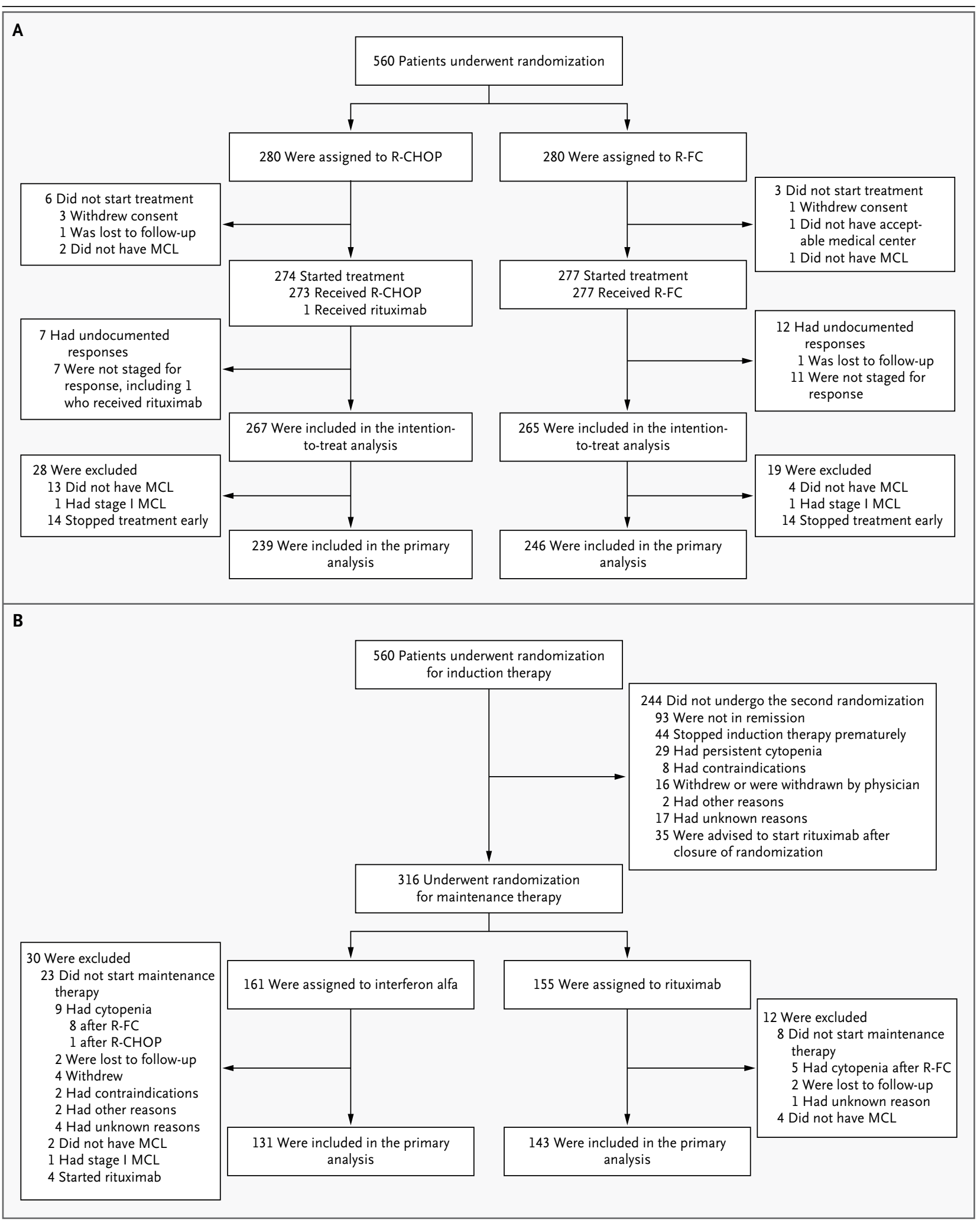

The New England Journal of Medicine

Downloaded from nejm.org at VRIJE UNIVERSITEIT on October 29, 2013. For personal use only. No other uses without permission. 
Figure 1 (facing page). Randomization and Inclusion in the Intention-to-Treat and Primary-Analysis Populations for Induction and Maintenance Therapy.

Panel A shows the first randomization phase, for induction therapy. Panel B shows the second randomization phase, for maintenance therapy. Details regarding reasons for exclusion are provided in Figure IA in the Supplementary Appendix. Patients who stopped treatment early ("premature stop," defined as discontinuation of the induction therapy before the midterm point in the absence of progression or discontinuation after less than two thirds of the cycles had been completed in patients with a response) were included in the intention-to-treat analysis but were not included in the primary analysis. $\mathrm{MCL}$ denotes mantle-cell lymphoma; R-CHOP rituximab, cyclophosphamide, doxorubicin, vincristine, and prednisone; and R-FC rituximab, fludarabine, and cyclophosphamide.

causes (13 and 9). Notably, 29 patients (10\%) who received R-FC died while in remission, as compared with 11 (4\%) who received R-CHOP. Owing to the observed difference in overall survival, the independent data and safety monitoring committee recommended closing the R-FC group.

Hematologic toxic effects occurred more frequently in the R-FC group than in the R-CHOP group (Table 2). Grade 1 or 2 constipation and neuropathy were more frequent among patients who received R-CHOP than among those who received R-FC. Grade 3 or 4 infections were balanced between the R-FC and R-CHOP groups, occurring in $17 \%$ and $14 \%$ of patients, respectively, but there was a trend toward a higher frequency of febrile neutropenia among patients who received R-CHOP than among those who received R-FC ( $17 \%$ vs. $11 \%, P=0.052)$. Cardiac toxic effects of grade 3 or 4 were uncommon, occurring in 3 to $4 \%$ of all patients, and the rates were similar in the two groups.

Owing to higher rates of hematologic toxic effects, treatment compliance was worse among patients who received R-FC: $23 \%$ of these patients who had a response did not complete all cycles, as compared with $12 \%$ of those who received $\mathrm{R}-\mathrm{CHOP}$ and had a response. The median duration of induction therapy in the R-FC group was 143 days (interquartile range, 106 to 161), as expected, with a median average cycle duration of 31 days; the median duration of induction therapy in the $\mathrm{R}-\mathrm{CHOP}$ group was 152 days (interquartile range,
147 to 163), as expected, with a median average cycle duration of 21 days.

\section{MAINTENANCE TREATMENT}

A total of 316 patients were randomly assigned to rituximab or interferon alfa, of whom 274 were included in the primary analysis (143 in the rituximab group and 131 in the interferon alfa group). The characteristics of the patients and reasons for not undergoing randomization or evaluation are shown in Figure $1 \mathrm{~B}$ and Table 1 and in Table S1 in the Supplementary Appendix. Persistent cytopenia in 29 patients who had received R-FC precluded participation in the second randomization, because maintenance therapy with interferon alfa required adequate hematopoietic function. For the primary analysis, censoring due to protocol violation occurred in eight cases, all in the group that received interferon alfa; 6 patients switched to maintenance therapy with rituximab, 1 to the combination of rituximab and interferon alfa, and 1 to radiotherapy. The median follow-up for assessment of the duration of remission was 36 months (37 months in the rituximab group and 34 months in the interferon alfa group).

The remission duration was significantly longer in the rituximab group than in the interferon alfa group, with a $45 \%$ reduction in the risk of progression or death according to the primary analysis (hazard ratio, $0.55 ; 95 \% \mathrm{CI}, 0.36$ to 0.87 ; $\mathrm{P}=0.01$, with adjustment for interim analyses) (Fig. S2B in the Supplementary Appendix). At 4 years, $58 \%$ of the patients who received rituximab were still in remission (50 events) versus $29 \%$ of those who received interferon alfa (71 events). The same effect was seen in the intention-to-treat analysis, with a 4-year rate of $57 \%$ in the rituximab group versus $34 \%$ in the interferon alfa group (Fig. 3A). Multivariable regression showed significantly different effects of rituximab according to the induction regimen $(\mathrm{P}=0.04)$ (Table $\mathrm{S} 3$ in the Supplementary Appendix). The influence of maintenance therapy with rituximab on the duration of remission was detected in patients who received R-CHOP but not in those who received R-FC (Fig. 3B, and Fig. S3A in the Supplementary Appendix).

The overall survival did not differ significantly between the maintenance groups: survival rates at 4 years were $79 \%$ in the rituximab group and $67 \%$ in the interferon alfa group ( $\mathrm{P}=0.13)$ (Fig. $3 \mathrm{C}$ ). 


\begin{tabular}{|c|c|c|c|c|c|c|}
\hline \multirow[t]{2}{*}{ Characteristic } & \multicolumn{3}{|c|}{ Induction Phase } & \multicolumn{3}{|c|}{ Maintenance Phase } \\
\hline & $\begin{array}{c}\text { Total } \\
(\mathrm{N}=485)\end{array}$ & $\begin{array}{c}R-F C \\
(N=246)\end{array}$ & $\begin{array}{l}\text { R-CHOP } \\
(\mathrm{N}=239)\end{array}$ & $\begin{array}{c}\text { Total } \\
(\mathrm{N}=274)\end{array}$ & $\begin{array}{l}\text { Rituximab } \\
(\mathrm{N}=143)\end{array}$ & $\begin{array}{l}\text { Interferon Alfa } \\
\quad(N=131)\end{array}$ \\
\hline \multicolumn{7}{|l|}{ Age $-y r$} \\
\hline Median & 70 & 70 & 70 & 70 & 69 & 71 \\
\hline Range & $60-87$ & $60-83$ & $61-87$ & $60-83$ & $60-81$ & $60-83$ \\
\hline Male sex - no. (\%) & $340(70)$ & $178(72)$ & $162(68)$ & $193(70)$ & $98(69)$ & $95(73)$ \\
\hline \multicolumn{7}{|l|}{ Ann Arbor stage - no. (\%) } \\
\hline II & $30(6)$ & $18(7)$ & $12(5)$ & $17(6)$ & $7(5)$ & $10(8)$ \\
\hline III & $55(11)$ & $30(12)$ & $25(10)$ & $34(12)$ & $17(12)$ & $17(13)$ \\
\hline IV & $400(82)$ & $198(80)$ & $202(85)$ & $223(81)$ & $119(83)$ & $104(79)$ \\
\hline Systemic symptom — no. (\%) $\dagger$ & $182(38)$ & $93(38)$ & $89(37)$ & $103(38)$ & $57(40)$ & $46(35)$ \\
\hline ECOG performance status of $2-$ no. $(\%) \ddagger$ & $39(8)$ & $21(9)$ & $18(8)$ & $13(5)$ & $3(2)$ & $10(8)$ \\
\hline Bone-marrow involvement — no. (\%) & $364(75)$ & $182(74)$ & $182(76)$ & $202(74)$ & $104(73)$ & $98(75)$ \\
\hline LDH elevation - no. (\%) & $206(42)$ & $104(42)$ & $102(43)$ & $99(36)$ & $55(38)$ & $44(34)$ \\
\hline Median ratio of LDH activity to ULN & 0.94 & 0.93 & 0.95 & 0.89 & 0.90 & 0.89 \\
\hline Median leukocyte count $-\times 10^{-9} /$ liter & 7.8 & 7.7 & 7.9 & 7.5 & 7.6 & 7.1 \\
\hline \multicolumn{7}{|l|}{ MIPI } \\
\hline Median score & 6.20 & 6.20 & 6.18 & 6.13 & 6.15 & 6.13 \\
\hline Low risk — no. (\%) & $42(9)$ & $24(10)$ & $18(8)$ & $26(9)$ & $13(9)$ & $13(10)$ \\
\hline Intermediate risk — no. (\%) & $201(41)$ & $98(40)$ & $103(43)$ & $129(47)$ & $64(45)$ & $65(50)$ \\
\hline High risk — no. (\%) & $242(50)$ & $124(50)$ & $118(49)$ & $119(43)$ & $66(46)$ & $53(40)$ \\
\hline Received R-CHOP — no. (\%) & NA & NA & NA & $163(59)$ & $82(57)$ & $81(62)$ \\
\hline $\begin{array}{l}\text { Complete remission, excluding unconfirmed } \\
\qquad \text { - no. (\%) }\end{array}$ & NA & NA & NA & $119(43)$ & $70(49)$ & $49(37)$ \\
\hline $\begin{array}{l}\text { Complete remission, including unconfirmed } \\
\qquad- \text { no. (\%) }\end{array}$ & NA & NA & NA & $167(61)$ & $89(62)$ & $78(60)$ \\
\hline
\end{tabular}

* P $>0.05$ for all comparisons. All variables were evaluated before the start of induction therapy. LDH denotes lactate dehydrogenase; NA not applicable; R-CHOP rituximab, cyclophosphamide, doxorubicin, vincristine, and prednisone; R-FC rituximab, fludarabine, and cyclophosphamide; and ULN upper limit of the normal range.

$\uparrow$ Systemic symptoms were defined as B symptoms in the Ann Arbor classification.

$\checkmark$ Scores on the Eastern Cooperative Oncology Group (ECOG) performance status range from 0 to 5 , with 0 indicating asymptomatic, 1 symptomatic but ambulatory, and 2 symptomatic and in bed less than half the day; 5 indicates death.

$\int$ The Mantle-Cell Lymphoma International Prognostic Index ${ }^{15}$ (MIPI) score is calculated from the individual patient characteristics of age, ECOG performance status, LDH, and leukocyte count, and its range depends on the range of these characteristics. Typical scores range from 4 to 10, with higher scores indicating higher-risk disease. The index classifies patients as having low-, intermediate-, or high-risk disease (see the Supplementary Appendix).

However, there was a significant modification of the effect of maintenance therapy according to the induction regimen $(\mathrm{P}=0.02)$ (Table $\mathrm{S} 3$ in the Supplementary Appendix), with a survival gain at 4 years among the patients who received R-CHOP (87\% in the rituximab group vs. $63 \%$ in the interferon alfa group; $\mathrm{P}=0.005$ ) (Fig. 3D) but not among the patients who received R-FC $(\mathrm{P}=0.48)$ (Fig. S3B in the Supplementary Appendix).
Toxic effects during the maintenance phase were more pronounced in the interferon alfa group, with more patients having leukocytopenia, thrombocytopenia, and fatigue, mostly of grade 1 or 2, whereas rituximab was associated with more grade 1 or 2 infections (Table 2). Adherence to treatment reflected these observed differences. Overall, the median duration of maintenance therapy was 25 months with rituximab versus 
7 months with interferon alfa. After 1 year, maintenance therapy with interferon alfa had been stopped in $49 \%$ of patients while they were in remission, whereas after 4 years, a premature stop of maintenance therapy with rituximab had occurred in only $28 \%$ of patients. A total of 35 patients who had a response were recommended for treatment with rituximab after closure of the randomization for maintenance therapy.

\section{DISCUSSION}

This randomized trial, coordinated within the European Mantle Cell Lymphoma Network, focused on older patients with mantle-cell lymphoma. Our results show that the fludarabine-containing induction regimen was not more effective but was more toxic than R-CHOP. Maintenance therapy with rituximab almost doubled the duration of remission in patients who had a response to induction therapy and significantly improved overall survival among patients who had a response to R-CHOP.

The outcome of the fludarabine-containing regimen was disappointing, given the high expectations in the early 2000s. We powered the study to detect an absolute increase of 15 percentage points in the rate of complete remission with R-FC, assuming that more complete remissions would result in a longer duration of remission and better overall survival. The increase in early progressions was unexpected and resulted - in combination with more toxic events - in more deaths. Both the poor performance of the R-FC regimen itself and insufficient hematopoietic recovery during and after the induction phase were responsible for the fact that fewer patients who received this regimen were eligible for the maintenance phase. Similar serious toxic effects, including severe and sometimes fatal adverse events, were reported with fludarabine and cyclophosphamide in patients with chronic lymphocytic leukemia, and therefore, this regimen was not considered suitable for patients who were older than 70 years of age or who had two or more coexisting conditions. ${ }^{16,17}$ One possible criticism of the R-FC regimen in our trial is that it provided less dose-dense rituximab than did the R-CHOP regimen: one dose every 28 days for six cycles versus one dose every 21 days for eight cycles. However, we assumed that this difference would be inconsequential.

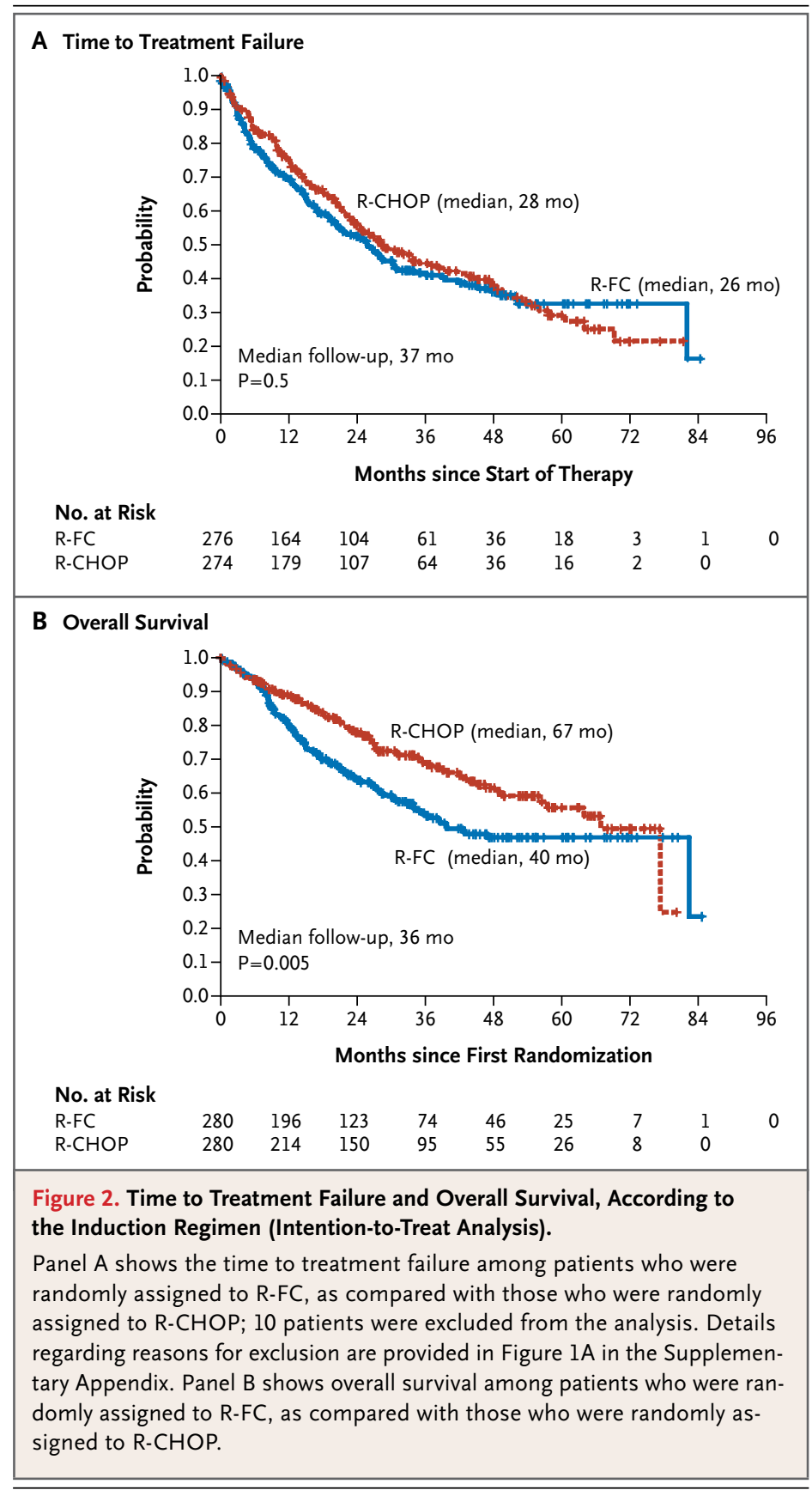

The excellent results with rituximab administered as maintenance therapy are important. Maintenance therapy with rituximab showed not only a progression-free survival benefit but also a significant survival advantage among patients who were successfully pretreated with R-CHOP. The protocol specification that maintenance therapy should continue until progression, which had been 
based on the poor outcome of salvage treatments in patients with relapsed mantle-cell lymphoma, was followed in the majority of patients who received maintenance therapy with rituximab. One might argue that the excellent outcome of maintenance therapy with rituximab was due solely to the poor performance of interferon alfa. However, our results with interferon alfa are better than or in line with those of previous trials. ${ }^{18,19}$ Moreover, a decrease in progression-free survival associated with interferon alfa has not been reported from any trial. Finally, we performed an intention-totreat analysis that included the 83 patients who had a response and who, before closure of the second randomization, were not randomly assigned to either maintenance regimen (none of whom received maintenance therapy with interferon alfa), with adjustment for risk profile as assessed with the use of Mantle-Cell Lymphoma International Prognostic Index ${ }^{15}$ (see the Supplementary Appendix) and category of response (Fig. S4 and Table S4 in the Supplementary Appendix). The duration of remission and overall survival time after a response to R-CHOP were significantly shorter among patients who were not assigned to any maintenance therapy, as compared with those

\begin{tabular}{|c|c|c|c|c|c|c|c|c|}
\hline Event & $\begin{array}{c}\text { R-FC } \\
(N=268)\end{array}$ & $\begin{array}{l}\text { R-CHOP } \\
(\mathrm{N}=249)\end{array}$ & $\begin{array}{c}\text { Rituximab } \\
(\mathrm{N}=140)\end{array}$ & $\begin{array}{c}\text { R-FC + } \\
\text { Rituximab } \\
(\mathrm{N}=59)\end{array}$ & $\begin{array}{l}\text { R-CHOP + } \\
\text { Rituximab } \\
(\mathrm{N}=81)\end{array}$ & $\begin{array}{c}\text { Interferon } \\
\text { Alfa } \\
(\mathrm{N}=117)\end{array}$ & $\begin{array}{c}\text { R-FC + } \\
\text { Interferon } \\
\text { Alfa } \\
(\mathrm{N}=43)\end{array}$ & $\begin{array}{c}\text { R-CHOP + } \\
\text { Interferon } \\
\text { Alfa } \\
(\mathbf{N}=74)\end{array}$ \\
\hline & \multicolumn{8}{|c|}{ percentage of patients with event of maximal grade } \\
\hline \multicolumn{9}{|l|}{ Anemia } \\
\hline Grade 1 or 2 & 59 & 68 & 41 & 53 & 32 & 42 & 52 & 36 \\
\hline Grade 3 or 4 & 20 & $12 \dagger$ & 4 & 5 & 4 & 4 & 10 & 0 \\
\hline \multicolumn{9}{|l|}{ Leukocytopenia } \\
\hline Grade 1 or 2 & 18 & 29 & 49 & 46 & 51 & 50 & 37 & 58 \\
\hline Grade 3 or 4 & 73 & $59 \dagger$ & 19 & 39 & 4 & $33 \sqrt{\int}$ & 60 & 18 \\
\hline \multicolumn{9}{|l|}{ Lymphocytopenia } \\
\hline Grade 1 or 2 & 9 & 19 & 33 & 15 & 46 & 24 & 12 & 31 \\
\hline Grade 3 or 4 & 78 & $69 ٪$ & 45 & 69 & 27 & 60 & 81 & 46 \\
\hline \multicolumn{9}{|l|}{ Neutropenia } \\
\hline Grade 1 or 2 & 18 & 20 & 27 & 27 & 28 & 29 & 21 & 34 \\
\hline Grade 3 or 4 & 69 & 60 & 24 & 37 & 15 & 36 & 64 & 19 \\
\hline \multicolumn{9}{|c|}{ Thrombocytopenia } \\
\hline Grade 1 or 2 & 39 & 33 & 27 & 47 & 13 & 42 & 44 & 40 \\
\hline Grade 3 or 4 & 41 & 189 & 6 & 14 & 1 & $15 \sqrt{\pi}$ & 33 & 4 \\
\hline \multicolumn{9}{|l|}{ Elevated bilirubin } \\
\hline Grade 1 or 2 & 15 & 8 & 7 & 8 & 6 & 8 & 10 & 7 \\
\hline Grade 3 or 4 & 1 & $1 †$ & 0 & 0 & 0 & 0 & 0 & 0 \\
\hline \multicolumn{9}{|l|}{ Nausea } \\
\hline Grade 1 or 2 & 36 & 26 & 11 & 17 & 6 & 15 & 21 & 11 \\
\hline Grade 3 or 4 & 2 & $1 †$ & 0 & 0 & 0 & 0 & 0 & 0 \\
\hline \multicolumn{9}{|l|}{ Constipation } \\
\hline Grade 1 or 2 & 15 & 28 & 7 & 8 & 6 & 7 & 7 & 7 \\
\hline Grade 3 or 4 & 2 & $3 \hbar$ & 1 & 2 & 0 & 0 & 0 & 0 \\
\hline
\end{tabular}




\begin{tabular}{|c|c|c|c|c|c|c|c|c|}
\hline \multicolumn{9}{|l|}{ Table 2. (Continued.) } \\
\hline Event & $\begin{array}{c}\mathrm{R}-\mathrm{FC} \\
(\mathrm{N}=268)\end{array}$ & $\begin{array}{l}\text { R-CHOP } \\
(\mathrm{N}=249)\end{array}$ & $\begin{array}{r}\text { Rituximab } \\
(\mathrm{N}=140) \\
\text { percento }\end{array}$ & $\begin{array}{c}\text { R-FC + } \\
\text { Rituximab } \\
(\mathrm{N}=59) \\
\text { of patients w }\end{array}$ & $\begin{array}{l}\text { R-CHOP + } \\
\text { Rituximab } \\
(\mathrm{N}=81)\end{array}$ & $\begin{array}{l}\text { Interferon } \\
\text { Alfa } \\
(\mathbf{N}=117) \\
\\
\text { al grade }\end{array}$ & $\begin{array}{c}\text { R-FC + } \\
\text { Interferon } \\
\text { Alfa } \\
(\mathrm{N}=43)\end{array}$ & $\begin{array}{c}\text { R-CHOP + } \\
\text { Interferon } \\
\text { Alfa } \\
(\mathrm{N}=74)\end{array}$ \\
\hline \multicolumn{9}{|l|}{ Neuropathy } \\
\hline Grade 1 or 2 & 7 & 36 & 14 & 3 & 23 & 14 & 7 & 18 \\
\hline Grade 3 or 4 & 1 & 49 & 1 & 2 & 0 & 1 & 0 & 1 \\
\hline \multicolumn{9}{|l|}{ Fatigue } \\
\hline Grade 1 or 2 & 50 & 52 & 28 & 25 & 29 & 48 & 41 & 51 \\
\hline Grade 3 or 4 & 4 & 6 & 1 & 3 & 0 & $5 \|$ & 10 & 3 \\
\hline \multicolumn{9}{|l|}{ Infection } \\
\hline Grade 1 or 2 & 18 & 31 & 31 & 36 & 27 & 17 & 21 & 14 \\
\hline Grade 3 or 4 & 17 & $14 \succcurlyeq$ & 9 & 14 & 5 & $11 * *$ & 12 & 11 \\
\hline \multicolumn{9}{|l|}{ Myalgia or arthralgia } \\
\hline Grade 1 or 2 & 9 & 12 & 14 & 15 & 13 & 19 & 12 & 22 \\
\hline Grade 3 or 4 & 0 & $3 \uparrow$ & 1 & 0 & 1 & 3 & 2 & 3 \\
\hline Febrile neutropenia†† & 11 & 17 & 3 & 5 & 1 & 4 & 10 & 1 \\
\hline \multicolumn{9}{|c|}{$\begin{array}{l}\text { Adverse events were graded according to the Common Terminology Criteria for Adverse Events, version 2.0. The maximal g } \\
\text { highest grade of adverse event that a patient had during the treatment period; patients were included only in the percentage fo } \\
\text { grade of event they had. The following events were associated with no significant difference between the two induction regime } \\
\text { the two maintenance regimens and were grade } 3 \text { or } 4 \text { in } 0 \text { to } 8 \% \text { of patients: elevated creatinine, elevated aminotransferase } \\
\text { diarrhea, mucositis, decreased cardiac function, decreased pulmonary function, depression, allergy, weight loss, and bleedi } \\
\mathrm{P}<0.05 \text { for adverse events of maximal grade } 0 \text { versus grade } 1 \text { or } 2 \text { versus grade } 3 \text { or } 4 \text { for R-FC versus R-CHOP. } \\
P<0.01 \text { for adverse events of maximal grade } 0 \text { versus grade } 1 \text { or } 2 \text { versus grade } 3 \text { or } 4 \text { for R-FC versus R-CHOP. } \\
P<0.01 \text { for adverse events of maximal grade } 0 \text { versus grade } 1 \text { or } 2 \text { versus grade } 3 \text { or } 4 \text { for rituximab versus interferon alfa. } \\
P<0.001 \text { for adverse events of maximal grade } 0 \text { versus grade } 1 \text { or } 2 \text { versus grade } 3 \text { or } 4 \text { for R-FC versus R-CHOP. } \\
P<0.001 \text { for adverse events of maximal grade } 0 \text { versus grade } 1 \text { or } 2 \text { versus grade } 3 \text { or } 4 \text { for rituximab versus interferon alfa. } \\
\text { P } P<0.05 \text { for adverse events of maximal grade } 0 \text { versus grade } 1 \text { or } 2 \text { versus grade } 3 \text { or } 4 \text { for rituximab versus interferon alfa. }\end{array}$} \\
\hline
\end{tabular}

who were randomly assigned to interferon alfa $(\mathrm{P}=0.002$ and $\mathrm{P}<0.001$, respectively). Although these data are not based on a randomized comparison, we believe that they strongly support the use of maintenance therapy with rituximab in older patients who have a response to R-CHOP.

Although our data are promising, patients still died from this lymphoma during the induction and maintenance phases. Thus far, standard first-line therapy for younger patients - consisting of highdose cytarabine, followed by autologous stem-cell transplantation - is generally not feasible for older patients. On the other hand, cytarabine seems to be one of the most important drugs in the treatment of mantle-cell lymphoma, ${ }^{2,20,21}$ and adapted doses appear to be feasible for older patients with relapsed mantle-cell lymphoma. ${ }^{22}$ Bendamustine-based treatment has been reported to be active against mantle-cell lymphoma on the basis of a subgroup analysis in a German first-line trial. ${ }^{23}$ Thus, bendamustine-containing combinations or molecular-targeted approaches that have shown high response rates among patients with relapsed mantle-cell lymphoma might be alternative induction regimens. ${ }^{22,24-26}$ Similarly, it may be attractive to combine the rituximab-based maintenance regimen with other drugs that have been shown to be active against mantle-cell lymphoma. However, physicians need to be aware of the potential interactions between the initial therapy and the maintenance regimen.

In conclusion, older patients with mantle-cell 


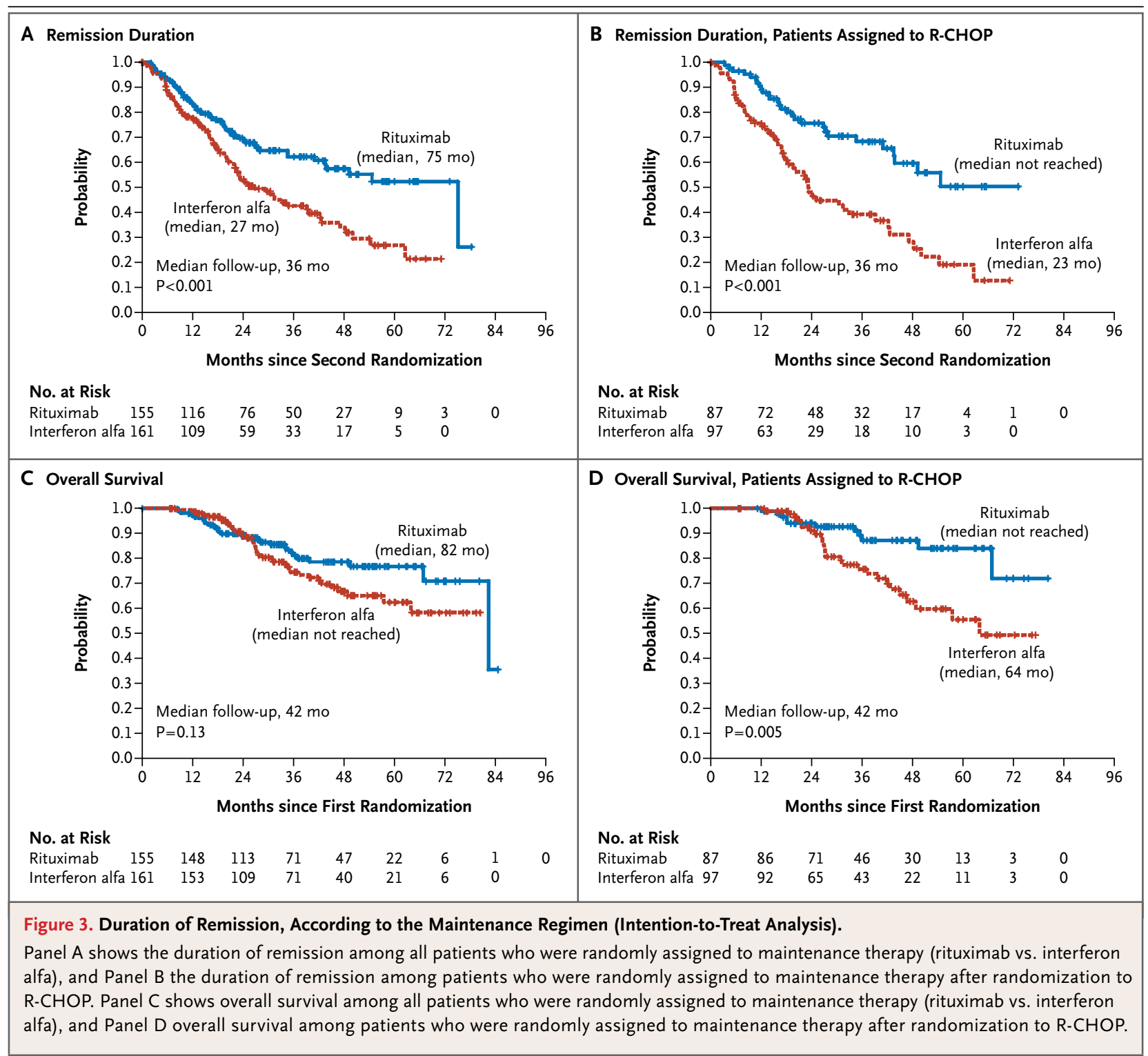

lymphoma who have a response to R-CHOP and continue to receive rituximab as maintenance therapy have a longer life expectancy than those who receive maintenance therapy with interferon alfa.
Supported by grants from the European Commission (LSHCCT-2004-503351), the Lymphoma Research Foundation, Roche Pharmaceuticals, Bayer Schering Pharma, and Schering-Plough.

Disclosure forms provided by the authors are available with the full text of this article at NEJM.org.

\section{APPENDIX}

The full names of the authors, and their degrees, are as follows: Hanneke C. Kluin-Nelemans, M.D., Ph.D., Eva Hoster, Ph.D., Olivier Hermine, M.D., Ph.D., Jan Walewski, M.D., Ph.D., Marek Trneny, M.D., Christian H. Geisler, M.D., Ph.D., Stephan Stilgenbauer, M.D., Catherine Thieblemont, M.D., Ph.D., Ursula Vehling-Kaiser, M.D., Jeanette K. Doorduijn, M.D., Ph.D., Bertrand Coiffier, M.D., Roswitha Forstpointner, M.D., Herve Tilly, M.D., Lothar Kanz, M.D., Pierre Feugier, M.D., Ph.D., Michal Szymczyk, M.D., Michael Hallek, M.D., Stephan Kremers, M.D., Gerard Lepeu, M.D., Laurence Sanhes, M.D., Josée M. Zijlstra, M.D., Ph.D., Redah Bouabdallah, M.D., Pieternella J. Lugtenburg, M.D., Ph.D., Margaret Macro, M.D., Michael Pfreundschuh, M.D., Vít Procházka, M.D., Ph.D., Francesco Di Raimondo, M.D., Vincent Ribrag, M.D., Michael Uppenkamp, M.D., Marc André, M.D., Wolfram Klapper, M.D., Wolfgang Hiddemann, M.D., Ph.D., Michael Unterhalt, M.D., Ph.D., and Martin H. Dreyling, M.D.

The authors' affiliations are as follows: the Department of Hematology, University Medical Center Groningen, University of Groningen, Groningen (H.C.K.-N.), Department of Hematology, Erasmus University Medical Center/Daniel den Hoed Cancer Center, Rotterdam (J.K.D.), Department of Hematology, VU University Medical Center, Amsterdam (J.M.Z.), and Department of Hematology, Erasmus University Medical Center, Rotterdam (P.J.L.) — all in the Netherlands; the Department of Internal Medicine III, University Hospital, 
Munich (E.H., R.F., W.H., M. Unterhalt, M.H.D.), Department of Internal Medicine III, University of Ulm, Ulm (S.S.), Tagesklinik Hämatologie Onkologie, Landshut (U.V.-K.), Department of Medicine II, University of Tübingen, Tübingen (L.K.), Klinik I für Innere Medizin, Universität Köln, Cologne (M.H.), Onkologisches Zentrum, Caritas Krankenhaus, Lebach (S.K.), Innere Medizin I, Universitätsklinik des Saarlandes, Homburg (M.P.), Medizinische Klinik A, Klinikum der Stadt, Ludwigshafen (M. Uppenkamp), and the Department of Pathology, Hematopathology Section and Lymph Node Registry, University of Kiel, Kiel (W.K.) - all in Germany; the Department of Hematology, Hôpital Necker, Assistance Publique-Hôpitaux de Paris, University Paris Descartes, Paris (O.H.), Department of Hematology, Hôpital Saint Louis, Paris (C.T.), Department of Hematology, Centre Hospitalier Lyon-Sud, Pierre-Benite (B.C.), Centre Henri Becquerel, Rouen (H.T.), Service d'Hématologie, Vandoevre-lès-Nancy (P.F.), Centre Hospitalier Henri Duffaut, Avignon (G.L.), Centre Hospitalier Maréchal Joffre, Perpignan (L.S.), Service d'Hématologie, Marseille (R.B.), Service d'Hématologie, Caen (M.M.), and Institut Gustave Roussy, Villejuif (V.R.) - all in France; the Department of Lymphoproliferative Diseases, Maria Sklodowska-Curie Memorial Institute and Cancer Center, Warsaw, Poland (J.W., M.S.); the Department of Medicine I, Charles University General Hospital, Prague (M.T.), and the Department of Hemato-Oncology, Faculty of Medicine and Dentistry, Palacky University, Olomouc (V.P.) - both in the Czech Republic; the Department of Hematology, Rigshospitalet, Copenhagen (C.H.G.); Divisione di Ematologia, Ospedale Ferratotto, Catania, Italy (F.D.R.); and Service d'Hématologie, Centre Hospitalier Universitaire Mont-Godinne, Yvoir, Belgium (M.A.).

REFERENCES

1. Swerdlow SH, Campo E, Seto $M$, Muller-Hermelink H-K. Mantle cell lymphoma. In: Swerdlow SH, Campo E, Harris NL, et al., eds. WHO classification of tumours of haematopoietic and lymphoid tissues. Lyon, France: IARC Press, 2008: 229-32.

2. Dreyling M, Hiddemann W. Current treatment standards and emerging strategies in mantle cell lymphoma. Hematology Am Soc Hematol Educ Program 2009;2009: 542-51. [Erratum, Hematology Am Soc Hematol Educ Program 2011;2011:562.]

3. Howard OM, Gribben JG, Neuberg DS, et al. Rituximab and CHOP induction therapy for newly diagnosed mantle-cell lymphoma: molecular complete responses are not predictive of progression-free survival. J Clin Oncol 2002;20:1288-94.

4. Hiddemann W, Dreyling M, Unterhalt M. Rituximab plus chemotherapy in follicular and mantle cell lymphomas Semin Oncol 2003;30:Suppl 2:16-20.

5. Foran JM, Rohatiner AZ, Coiffier B et al. Multicenter phase II study of fludarabine phosphate for patients with newly diagnosed lymphoplasmacytoid lymphoma, Waldenström's macroglobulinemia, and mantle-cell lymphoma. J Clin Oncol 1999;17:546-53.

6. Zinzani PL, Magagnoli M, Moretti L, et al. Randomized trial of fludarabine versus fludarabine and idarubicin as frontline treatment in patients with indolent or mantle-cell lymphoma. J Clin Oncol 2000; 18:773-9.

7. Forstpointner R, Dreyling M, Repp R, et al. The addition of rituximab to a combination of fludarabine, cyclophosphamide, mitoxantrone (FCM) significantly increases the response rate and prolongs survival as compared with FCM alone in patients with relapsed and refractory follicular and mantle cell lymphomas: results of a prospective randomized study of the German Low-Grade Lymphoma Study Group. Blood 2004;104:3064-71.

8. Cohen BJ, Moskowitz C, Straus D, Noy A, Hedrick E, Zelenetz A. Cyclophosphamide/fludarabine (CF) is active in the treatment of mantle cell lymphoma. Leuk Lymphoma 2001;42:1015-22.

9. Unterhalt M, Hermann R, Koch P, et al. Long term interferon alpha maintenance prolongs remission duration in advanced low grade lymphomas and is related to the efficacy of initial cytoreductive chemotherapy. Blood 1996;88:453a. abstract. 10. Forstpointner R, Unterhalt M, Dreyling $M$, et al. Maintenance therapy with rituximab leads to a significant prolongation of response duration after salvage therapy with a combination of rituximab, fludarabine, cyclophosphamide and mitoxantrone (R-FCM) in patients with relapsed and refractory follicular and mantle cell lymphomas: results of a prospective randomized study of the German Low Grade Lymphoma Study Group (GLSG). Blood 2006;108:4003-8.

11. Klapper W, Hoster E, Determann O, et al. $\mathrm{Ki}-67$ as a prognostic marker in mantle cell lymphoma - consensus guidelines of the pathology panel of the European MCL Network. J Hematop 2009;2:103-11. 12. The International Non-Hodgkin's Lymphoma Prognostic Factors Project. A predictive model for aggressive non-Hodgkin's lymphoma. N Engl J Med 1993;329:987-94. 13. Cheson BD, Horning SJ, Coiffier B, et al. Report of an international workshop to standardize response criteria for nonHodgkin's lymphomas. J Clin Oncol 1999; 17:1244-53. [Erratum, J Clin Oncol 2000; 18:2531.]

14. Whitehead JR. The design and analysis of sequential clinical trials. 2nd ed., rev. Chichester, United Kingdom: Wiley, 1997. 15. Hoster E, Dreyling M, Klapper W, et al. A new prognostic index (MIPI) for patients with advanced stage mantle cell lymphoma. Blood 2008;111:558-65. [Erratum, Blood 2008;111:5761.]

16. Catovsky D, Richards S, Matutes E, et al. Assessment of fludarabine plus cyclophosphamide for patients with chronic lymphocytic leukaemia (the LRF CLL4 Trial): a randomised controlled trial. Lancet 2007;370:230-9.

17. Eichhorst B, Goede V, Hallek $M$. Treatment of elderly patients with chronic lymphocytic leukemia. Leuk Lymphoma 2009;50:171-8.

18. Lenz G, Dreyling M, Hoster E, et al. Immunochemotherapy with rituximab and cyclophosphamide, doxorubicin, vincristine, and prednisone significantly improves response and time to treatment failure, but not long-term outcome in patients with previously untreated mantle cell lymphoma: results of a prospective randomized trial of the German Low Grade Lymphoma Study Group (GLSG). J Clin Oncol 2005;23:1984-92.

19. Dreyling M, Lenz G, Hoster E, et al. Early consolidation by myeloablative radiochemotherapy followed by autologous stem cell transplantation in first remission significantly prolongs progressionfree survival in mantle cell lymphoma: results of a prospective randomized trial of the European MCL network. Blood 2005;105:2677-84.

20. Geisler $\mathrm{CH}$. Front-line treatment of mantle cell lymphoma. Haematologica 2010;95:1241-3.

21. Harel S, Delarue R, Ribrag V, Dreyling $M$, Hermine O. Treatment of younger patients with mantle cell lymphoma. Semin Hematol 2011;48:194-207.

22. Weigert O, Weidmann E, Mueck R, et al. A novel regimen combining high dose cytarabine and bortezomib has activity in multiply relapsed and refractory mantle cell lymphoma - long-term results of a multicenter observation study. Leuk Lymphoma 2009;50:716-22.

23. Rummel MJ, Kaiser U, Balser C, et al. Bendamustine plus rituximab versus fludarabine plus rituximab in patients with relapsed follicular, indolent and mantle cell lymphoma: final results of the randomized phase III study NHL 2-2003 on behalf of the StiL (Study Group Indolent Lymphomas, Germany). In: Program and abstracts of the American Society of Hematology 52nd Annual Meeting, Orlando, FL, December 4-10, 2010:114. abstract.

24. Pérez-Galán P, Dreyling $M$, Wiestner A. Mantle cell lymphoma: biology, pathogenesis, and the molecular basis of treatment in the genomic era. Blood 2011;117:26-38. 25. Weigert O, Pastore A, Rieken M, Lang N, Hiddemann W, Dreyling M. Sequencedependent synergy of the proteasome inhibitor bortezomib and cytarabine in mantle cell lymphoma. Leukemia 2007;21:524-8.

26. Kluin-Nelemans HC, Doorduijn JK. Treatment of elderly patients with mantle cell lymphoma. Semin Hematol 2011;48: 208-13.

Copyright (C) 2012 Massachusetts Medical Society. 